\title{
How I Became TheKneejerkCritic
}

TRANSLATED BY JOEL DAVID

\section{Ricardo Espino Lopez}

GMA Network - Entertainment, Talk/Variety

Who is this self-important TheKneeJerkCritic who is presumptuous enough to review movies as if he had the qualifications to do so? The nerve! He said the nerve, right?...

The answer is, he is a self-published blogger. He does not read magazines, e-zines, or broadsheets. Even the tabloids steered clear.

TheKneeJerkCritic is a blog that focuses on reviewing local and foreign films, plus a few stage presentations, while using street-based off-thecuff language with more than just a sprinkling of bekinese or gay lingo. It is actually a spin-off of my earlier online alter ego, Ishna Vera [snobbish], which I started around 2006. My attempts as Ishna Vera were diverse and directionless and came out only occasionally. Only when I felt like acting up.

Ooops sorry, force of habit. I meant, only when I needed to state something.

My first "review" was not really even an actual review. It was more a reaction piece, my personal take on film as an experience rather than a review about the movie.

See Evidence A, an early sample of the groundbreaking pink indie film Antonio's Secret [directed by Joselito Altarejos, Beyond the Box \& Viva Digital, 2008]: 
I missed catching Antonio's Secret when the director's cut was shown last year I think. I managed to get hold of a copy recently and I excitedly popped it into the player.

The narrative of Antonio's Secret goes like this:

... fast-forward, fast-forward, fast-forward.... play, rewind, play, rewind, play ... fast-forward, fast-forward ... play, rewind, play, rewind, play ... fast-forward. Stop. Eject.

Ay! Was there a narrative? All right I'll try again some other time wehehe.

Well, apparently this kind of approach has its own readership because I eventually noticed that only when I had "reviews" was I able to get some online engagement from my friends, who made up the totality of my reading population at that point.

It was around April 2015 when it occurred to me to get into reviewing and write an entirely separate blog. Thus TheKneeJerkCritic was born.

So here is my first post as The Kneejerk Critic, a review of the critically acclaimed but Oscar-snubbed masterpiece Avengers: Age of Ultron [directed by Joss Whedon, Marvel Studios at Walt Disney Pictures, 2015], kidding: 
Here's the cheat sheet of the narrative of Age of Ultron:

Wham. Bam. Boom.

Yada-yada. Love angle. Yada-yada.

Boom. Bam. Wham. CGI efok.

Family stuff. Hairy chest of Mark Ruffalo. Yumminess-cum-emo.

Chase scene. Sprakatak. Tarakatat.

Stuff. More stuff. A naked Chris Helmsworth.

Jennylyn. Jennylyn. A robot whom I'll transform into a bald Bollywood actor with a magic bindi!

Am impressive multi-hero fight-scene tableau.

Kaboom. Kablam. Death scene for major emo moment.

Climactic finish.

Epilogue segue to introduction of Avengers 2.0.

Credits.

That was not an excerpt-that was the entire review. That was as much as I could give then. Do not clobber me because I was still a work in progress, $\mathrm{OK}$ ?

Kidding.

So what qualified me to review movies? Huwell, aside from paying the exorbitant movie ticket price, nothing. I just felt like acting up so lay off. Mind your own business.

Cards on the table. I have no bachelor, master's, much less a doctorate degree in film or film appreciation to give me any credibility as a reviewer. I never even completed college. So I totally have no credentials as a film critic. Zero. None. Zilch. Nada. I just like the activity.

Though my work in media places me near the bottom in the hierarchy of the entertainment industry, I don't have any connection with film production whatsoever. 
What I am is a movie fan.

Or make that, a fan of movies.

I do not have any delusions about becoming a film connoisseur. I do not worry if a specific release is a quirky indie film, or studio-released mainstream movie, o super-commercial fluff. I am no snob. Rom-com, sci-fi, superhero blockbuster, awards-bait, or anime, as long as it piques my curiosity, I will line up to watch it. Even an old reissue isn't out of my range of interests. Here is an excerpt of my review of Himala [directed by Ishmael Bernal, Experimental Cinema of the Philippines, 1982], which I watched 35 years after its original run.

The plot concerns barrio Cupang, a destitute rural village that the villagers themselves claim was cursed to droughtiness because they once banished a leper whom they later believed was Mama Mary in disguise.

You're screwed, you insulted the Mother of God!

Later, during a major-major solar eclipse, well look who wanted a return engagement at Cupang, none other than Mama Mary - but it was a limited edition because she revealed herself only to Elsa.

After which Elsa was visited by stigmata keme. Then, after that, healing powers were granted her royal queerness, I mean our visionary!

Like a low-rent callboy, the rumors of faith healing were passed on by word of mouth and before you know it, people with all kinds of ailment swooped down on Elsa's home followed by the paparazzi.

I would also gamble on movies that I were not sure were worth watching, especially indie films. That is because those films need my financial support as a viewer as well as any kind of exposure that I can provide as an online reviewer.

I also make an effort to binge-watch entries of local film fests like the Metro Manila Film Festival, Festival of Philippine Films, and Cinemalaya, in support of the local industry. Sometimes it turns out that the movie is a gem so I win my bet, sometimes it is awful so I lose. But for commercial movies, 
if I feel like I will just be disgusted, I just skip it since I don't intend to shell out money just to annoy myself. I'm queer, not dumb, OK?

As a viewer, I prefer movies that touch me emotionally. I have nothing against intellectual movies but I prefer to be titillated at the movies. I do not mind being made to cry either. I will appreciate a little intellectual effort with certain movies but too much, all right? I do not want movies that give me a headache, the ones that are too difficult to figure out and trying to be deep. You would know if something is high-falutin and the director is just showing off, right? Sorry, thank you next is my message to you then.

I also resent movies that make me feel like an idiot. Hello, I can do well enough making myself idiotic, right. Kidding.

But I am not too choosy. All I ask from a movie is that delivers what it promised. I can enjoy a shallow movie just as easily as a well-made heart-rending movie. The key is in managing my expectation. Better yet exceeding it. How many times do we hear the line "we poured all our efforts into this project" during some film's promotion and then we see some twattish result onscreen? You bunch of jerks.

As a reviewer, I look for the same thing, since you cannot really separate the viewer from the reviewer. There is just more to be done. My reviews are experiential rather than technical but occasionally after I finish watching the film seems OK to me, but as I write the review and pick it apart, ayyy I do not think I like it any longer.

The downside of watching a movie you plan to review, you cannot sit back and relax because you have to concentrate as you watch or you get a sudden insight for your review where you need to remember the phrasing and the context of the scene wherein you got the insight.

Also, whenever possible, I try to expand my mind as a reviewer. I read other movie reviews online, I study how to be more critical in my approach, and I watch and watch and watch.

So yes, though kneejerkcritic's my blog name and I recount a lot of my kneejerk reactions in my writing, I do not upload my reviews in the same manner. I spend some effort in figuring out what I write as a whole. 
There are still some considerations that I try to balance. Like if it is an indie film or stage presentation, as an advocate, I am more effusive in praising and somewhat kinder in dissing if I find it bad. I would say it is just a little bad. Hahaha.

But mainstream films are fair game. That is where I go to town, especially when the film just intends to function as a money-grubber. Let us tear that apart bodaciously when it deserves it! I will never say that I found a movie worthwhile just because a few respected critics say the same thing. If I found it hideous, then I'll call it hideous. Fight me. Kidding.

As in this review I wrote of the Dawn Zulueta and Piolo Pascual starrer titled Love Me Tomorrow [directed by Gino M. Santos, ABS-CBN Film Productions at Star Cinema, 2016]:

It's awful.

The shots are nice. It's glossy, well-framed. But awful.

The return-my-money, return-my-time level of awful.

\#lovemetomorrow? I didn't even like it today.

This must be the only movie where I wasn't bothered by the substandard audio at SM Cinemas because at a certain point I couldn't care less about the dialogue because I knew the rest would be worthless.

What a waste of visuals. A waste of Dawn Zululeta's charm. A waste of those abs of Papa Piolo Pascual. Sonofabitch you've got Ana Abad Santos in the cast, and you used her as a virtual flower vase in one corner, what gives?!!!

Honestly the best thing about the movie is the ending.... The movie's over. We can go home. The best.

Which now brings me to the language I use which I would describe as bekinese that is vulgar but tries to sound learned. ${ }^{1}$ Joking.

Though there are very few reviewers who deliver their critiques in a manner similar to mine, my choice of vocabulary is not unique. I have been inspired by not just a few blogs using the same mode of expression. The now 
inactive blog of Mandaya Moore comes to mind. So basically, as [film villain] Cherie Gil once said, "you're nothing but a second-rate, trying-hard copycat?"

It was a conscious decision for me to use and continue using bekinese as the primary mode of communication in my blog.

First, as the hookers-cum-strippers sang in Gypsy [directed by Mervyn LeRoy, Mervyn LeRoy Productions, 1962], “you gotta have a gimmick,” and that was the gimmick I picked. When I started the blog, all I wanted was to express myself and be read. The desire to be of service to industry came later, and by that time the blog's character and brand was fairly established. So now I am name-dropping brand pretending to understand it, eh?

Second, since I was trying to use my voice to serve the industry, my movie reviews had to be read and shared. And to be read and shared in this day and age, you have to entertain. Or at least shock and awe.

Third, I believe that movie reviews need to be read and enjoyed by the masses and not the few who can read and understand. What is this, a contest on who can use the most number of multi-syllabic words?

Fourth, with using street and bekinese language, I try to be their eyes and their voice. Hopefully the reviews would encourage the mass audience to go and watch, to inform them that there are these new types of films that are available for them to watch. And maybe, just maybe even educate them to be more critical in watching and more discerning in their choices of films they wish to support.

Fifth, I love the exercise. I am sold on finding ways to see a particular movie with a unique perspective. Or retelling the story in a different, more colorful light. If I am unable to convict [readers] to watch a film, then maybe the review itself might entertain you and make you laugh.

And if you do not find it funny, then fuck you all!

Kidding. Shock and Awe. 


\section{Translation Note}

1. Gay lingo. Beki, possibly from or reinforced by the US pop-culture meme "Becky" referencing white women proficient in oral sex (since modified by Beyoncé to mean a woman who privileges her whiteness-Michael Harriot, "The 5 Types of 'Becky”' in The Root, posted August 29, 2017; see also Suzannah Weiss, "Is 'Becky' Really a Racist Stereotype against White Women?" in Complex, posted April 29, 2016), emerged in local gay slang as an amelioration of bakla, a pejorative word for homosexual, originally meaning cowardly or confused in old Tagalog. 